\title{
Design of Intelligent Hanger Based on Single Chip and Pro-E
}

\author{
Xingjian Jia ${ }^{*}$ and Changbao Chu
}

Department of Mechanical and Electrical Engineering, Nanchang institute of Technology, Nanchang, China

\begin{abstract}
A new type of intelligent hanger was designed based on single chip and Pro-E software. 3D entity model of actuator and cover curtain mechanism are established by Pro-E. Wings structure of hanger mechanical part was adopted screw rod and motor combination of the lifting mechanism can make the wings outspread and fold, unique cover curtain structure was adopted. Cover curtain rolls up and down through the motor driving. The control system adopts AT89C52 single chip. According to the information that coming from the rain sensor and the temperature sensor, two stepper motor's positive and negative rotational motion was controlled. So as to realize automatic adjustment when it rains. The hanger will be automatically closed when the temperature is higher than expected, and the hanger will be automatically opened when the temperature is less than expected. The hanger that has been produced has a good performance.
\end{abstract}

Keywords: Intelligent Hanger, Rain Sensor, DS18B20 AT89C52, Singlechip.

\section{INTRODUCTION}

At present, traditional hanger only can dry and hang clothes; the function of rainproof hanger does not have too much at home and abroad. The hanger' applicable scope is narrow. The existing outdoor hanger is generally fixed on the wall or floor, rainproof telescopic hanger also is fixed on the wall [1]. At present, hand hanger and electric hanger appear in the market. Hand hanger installs complex and short service life. At the same time, installation costs of hand hanger are so high [2]. Electric drying hanger is expensive and is not in purchase reach. Through analysis of existing hanger, the function of traditional hanger is relatively simple, hanger's structure is complex, it is difficult to achieve and there are geographical constraints [3]. According to the deficiency, the paper designed the intelligent hanger based on AT89C52 single-chip microcomputer. The blank of removable intelligent hanger was filled.

\section{DESIGN OF NEW INTELLIGENT HANGER}

The existing hanger basically has the following categories, they are shown in Fig. (1).

At present, we can hardly see intelligent rainproof hanger on the market. Through analysis of existing hanger, the function of traditional hanger is relatively simple, hanger's structure is complex, it is difficult to achieve and there are geographical constraints [4].

In this paper, intelligent hanger is designed based on single-chip microcomputer and Pro-E. 3D entity model of intelligent hanger is established by Pro-E software. The control system adopts AT89C52 single-chip microcomputer. The intelligent hanger is produced which has a good Performance.

*Address correspondence to this author at the Department of mechanical and electrical engineering,Nanchang institute of technology, Nanchang, china; Tel: 13694881350;

Email: jiaxingjian2013@163.com

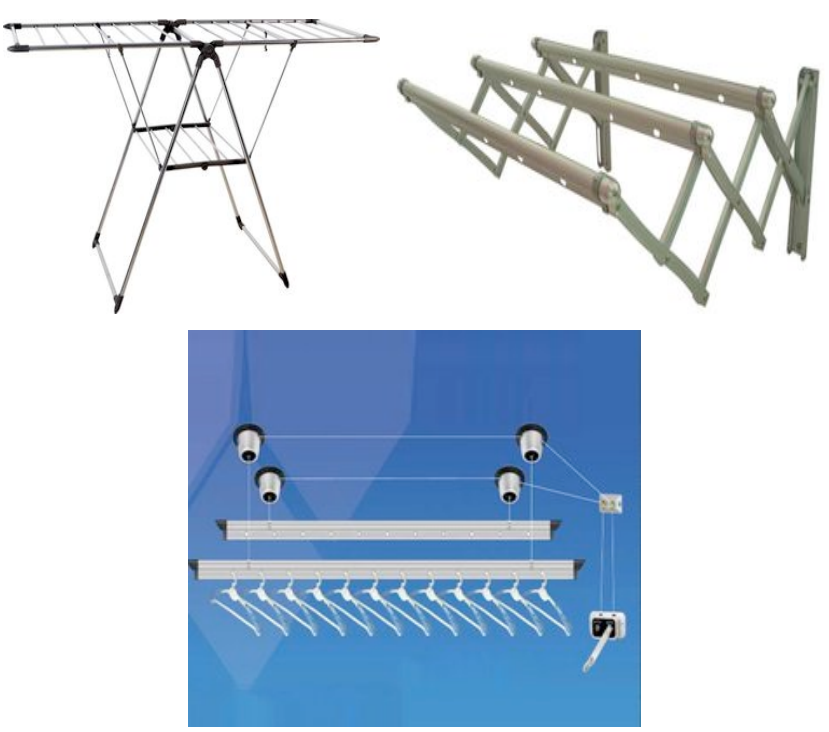

Fig. (1). Existing hanger.

\subsection{Working Principle}

Overall structure of new intelligent hanger is shown in Fig. (2).

The hanger is mainly composed of a machine frame, hanging hanger, screw rod, cover curtain, main motor and deputy motor. The function of the machine frame is to support the whole hanger. The function of the hanging hanger is to hang clothes, it can outspread and fold. The function of the screw rod is to drive the slider upward, the cover curtain is winded by two hollow tubes, the purpose of cover curtain is to cover clothes and avoid the rain. When it rains, the main motor drives screw rod rotation, screw rod drives screw rod slider decline, screw rod slider makes the hanger close up through the connecting rod. At the same time, the deputy motor drives cover curtain operation, makes the cover curtain down to avoid the rain to wet clothes. The sun shines 

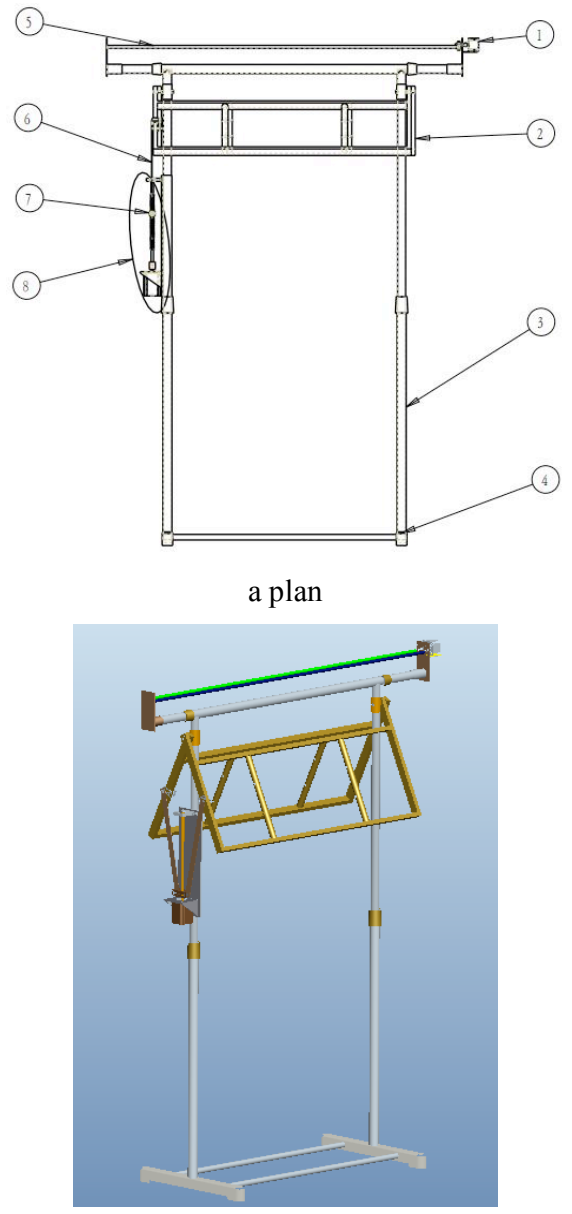

b 3D model diagram

1. gear motor 2 . hanger wing 3 . frame 4 . base 5 . reels 6 . connecting rod 7 . slider 8 . screw rod motor

Fig. (2). Overall structure of new intelligent hanger.
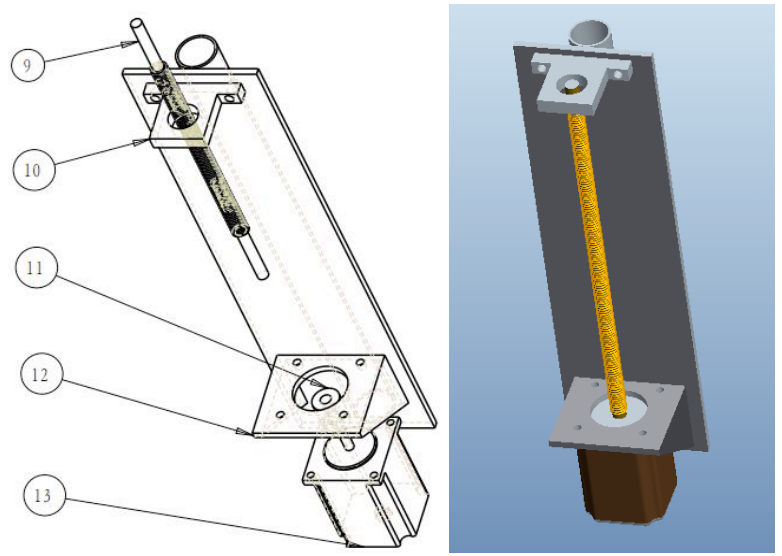

9. screw rod 10 . bearing 11 . couplings 12 . motor bearings 13 . main motor

Fig. (3). Structure of wings lifting mechanism

again after rain, the controller collects "sunny" signal coming from the rain sensor which makes the deputy motor reversal and drives cover curtain operation. The deputy motor makes the cover curtain upwards roll, and then the main motor drives screw rod reverse rotation. Screw rod drives screw rod slider rise, screw rod slider makes the hanger outspread
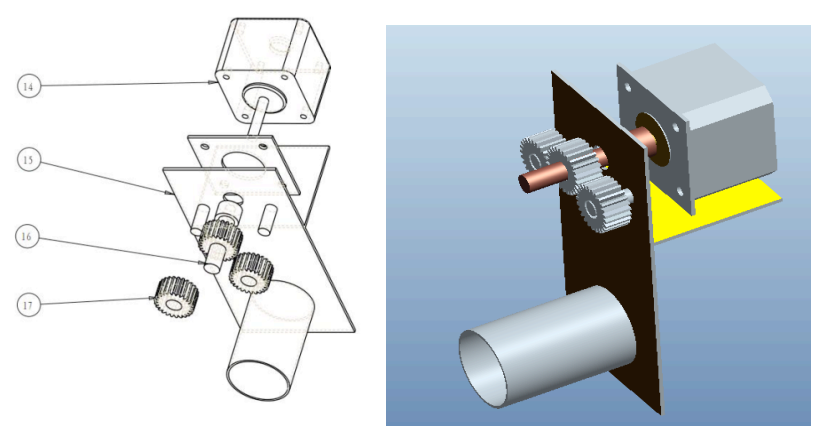

14.deputy motors, 15 . deputy motor bhangeret, 16 . sleeve, 17 . gears

Fig. (4). Structure of cover curtain mechanism

through the connecting rod. The function of drying clothes is achieved.

\subsection{Actuator Structure Design}

Intelligent hanger actuator is divided into two wings lifting mechanism and cover curtain mechanism. Schematic diagram of the structure design is shown in Fig. (3) and Fig. (4).

When it rains, the main motor drives screw rod rotation, screw rod drives screw rod slider decline, screw rod slider makes the hanger close up through the connecting rod. At the same time, the deputy motor drives cover curtain operation, makes the cover curtain down to avoid the rain to wet clothes. The sun shines again after rain, the controller collects "sunny" signal coming from the rain sensor, makes the deputy motor reversal and drives cover curtain operation. The deputy motor makes the cover curtain upwards roll, and then the main motor drives screw rod reverse rotation. Screw rod drives screw rod slider rise, screw rod slider makes the hanger outspread Through the connecting rod. The function of drying clothes is achieved [5, 6].

\subsection{Design Parameter}

\section{Hanger Overall Parameters}

Hanger height: $144 \mathrm{~cm}$, hanger width: $68 \mathrm{~cm}$, coat hanger length: $80 \mathrm{~cm}$, coat hanger width: $40 \mathrm{~cm}$, Clothes rod length: $30 \mathrm{~cm}$, cover curtain length: $108 \mathrm{~cm}$,vertical height: $156 \mathrm{~cm}$, screw rod length: $30 \mathrm{~cm}$,

Base parameters: length: $39 \mathrm{~cm}$, width: $21 \mathrm{~cm}$, height: $4 \mathrm{~cm}$,

Motor parameters: Main motor model: HY57DJ76 deputy motor model: HY42DJ34

screw rod:

self-locking condition:

Helix Angle

$\lambda=\operatorname{ArcTan}\left[\frac{\mathrm{S}}{\pi * \mathrm{~d} 2}\right]=\operatorname{ArcTan}\left[\frac{1.5}{\pi * 10.026}\right]=\operatorname{ArcTan}[0.048]=2.8^{\circ}$

Friction factor $\mathrm{f}=0.17$

Equivalent friction Angle $\rho=\operatorname{ArcTan}[0.17]=10^{\circ} \lambda(\rho$ Selflocking function can be achieved.

speed of main motor $250 \mathrm{rpm}$ 


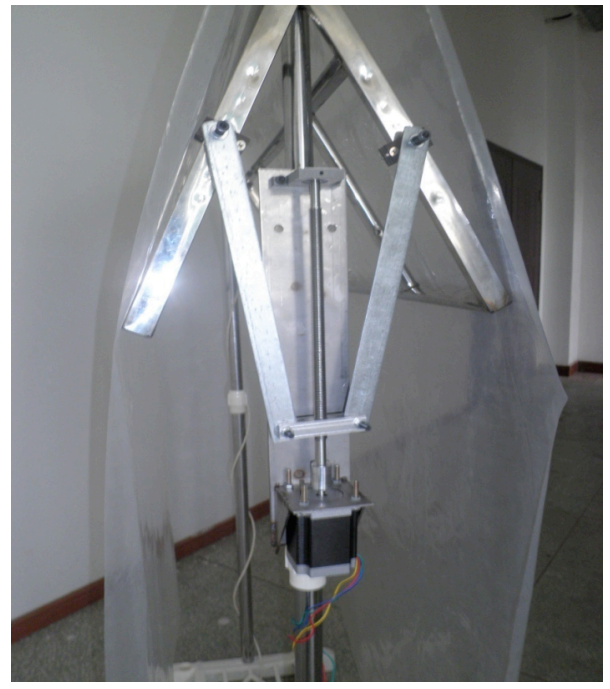

Fig. (5). Screw rod structure.

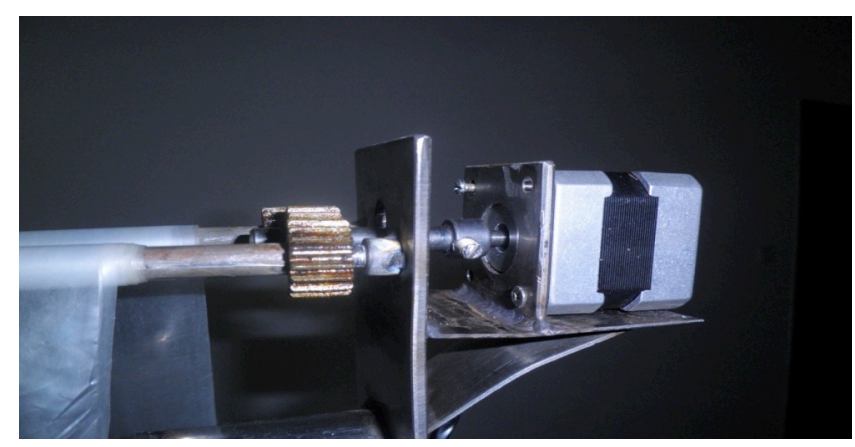

Fig. (6). Gear transmission structure of the cover curtain.

Transfer torque: $T=9550 * \frac{24 * 3 * 10^{-3}}{250}=2.75 N * M$

speed of deputy motor: $\mathrm{n}=105 \mathrm{rpm}$;

Transfer torque: $T=9550 * \frac{24 * 1.3 * 10^{-3}}{105}=2.84 N * M ;$ number of teeth $\mathrm{z}=18$ module $=1$ Bore diameter $=8 \mathrm{~mm}$ root circle diameter $=16 \mathrm{~mm}$ The addendum circle diameter $=20 \mathrm{~mm}$ transmission ratio $=1: 1$ :

Mechanical structure physical diagrams are shown in Fig. (5), the gear transmission structure of the cover curtain is shown in Fig. (6).

\section{CONTROL SYSTEM DESIGN}

Design of the control system comprises power supply circuit design, rain sensing control circuit and the temperature sensor control circuit design. Single chip microcomputer controls the stepper motor rotation reliably, namely, the hanger outspread and fold, the type of MCU: AT89C52. The type of main motor: HY57DJ76, the type of deputy motor: HY42DJ34. The principle diagram of the control system is shown in Fig. (7).

\subsection{Hardware Circuit Design}

\section{Power Supply Circuit Design}

Two pieces of $12 \mathrm{~V}$ battery as a power supply is adopted, it is easy to carry and can directly be used for motor power. The $+12 \mathrm{~V} \mathrm{DC}$ power is transformed into $+5 \mathrm{~V}$ DC which the controller can use. $+24 \mathrm{~V}$ DC power is directly supplied to stepper motor and its driver. First, voltage regulator chip 7809 transforms $+12 \mathrm{~V}$ DC into $+9 \mathrm{~V} \mathrm{DC}$, then voltage regulator chip 7805 transforms $+9 \mathrm{~V}$ DC into $+5 \mathrm{~V}$ DC. Power supply circuit is shown in Fig. (8). All kinds of capacitor is used to filter. F1 plays the role of short circuit protection. Light emitting diode indicates whether there is electricity [7].

\section{Rain Sensor Control Circuit}

Rain sensor of type SD-12Y is used to detect whether it rains or not, it can detect liquid, condensation, rain, damp air. The sensor adopts gold-plated humidity-sensitive film, it has the performance of high stability and high sensitivity. When the humidity is detected more than $70 \% \mathrm{HR}$, it will continuously output the information. It is applicable to condensation / liquid detection. Module normal operating voltage range: $2 \mathrm{~V}$ to $18 \mathrm{~V}$; Output form: Low level effective [8];

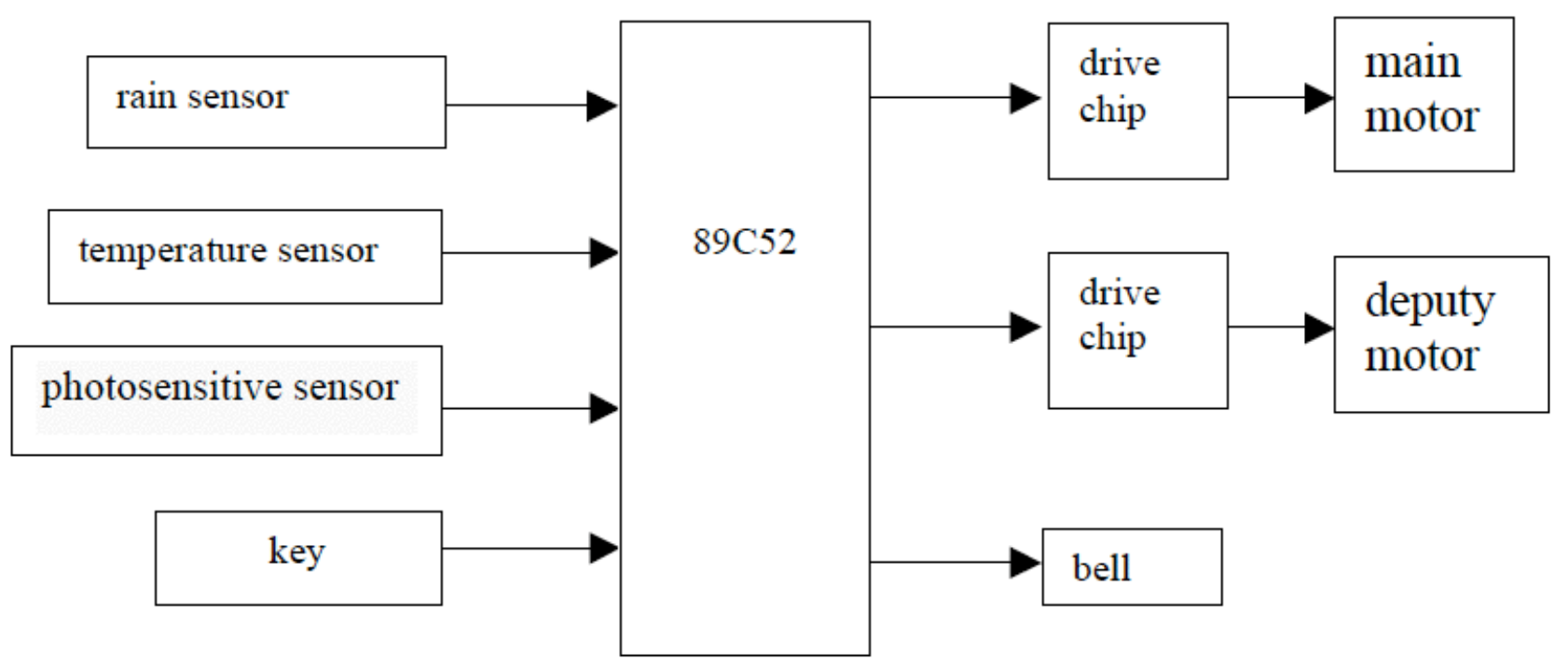

Fig. (7). Principle diagram of the control system. 


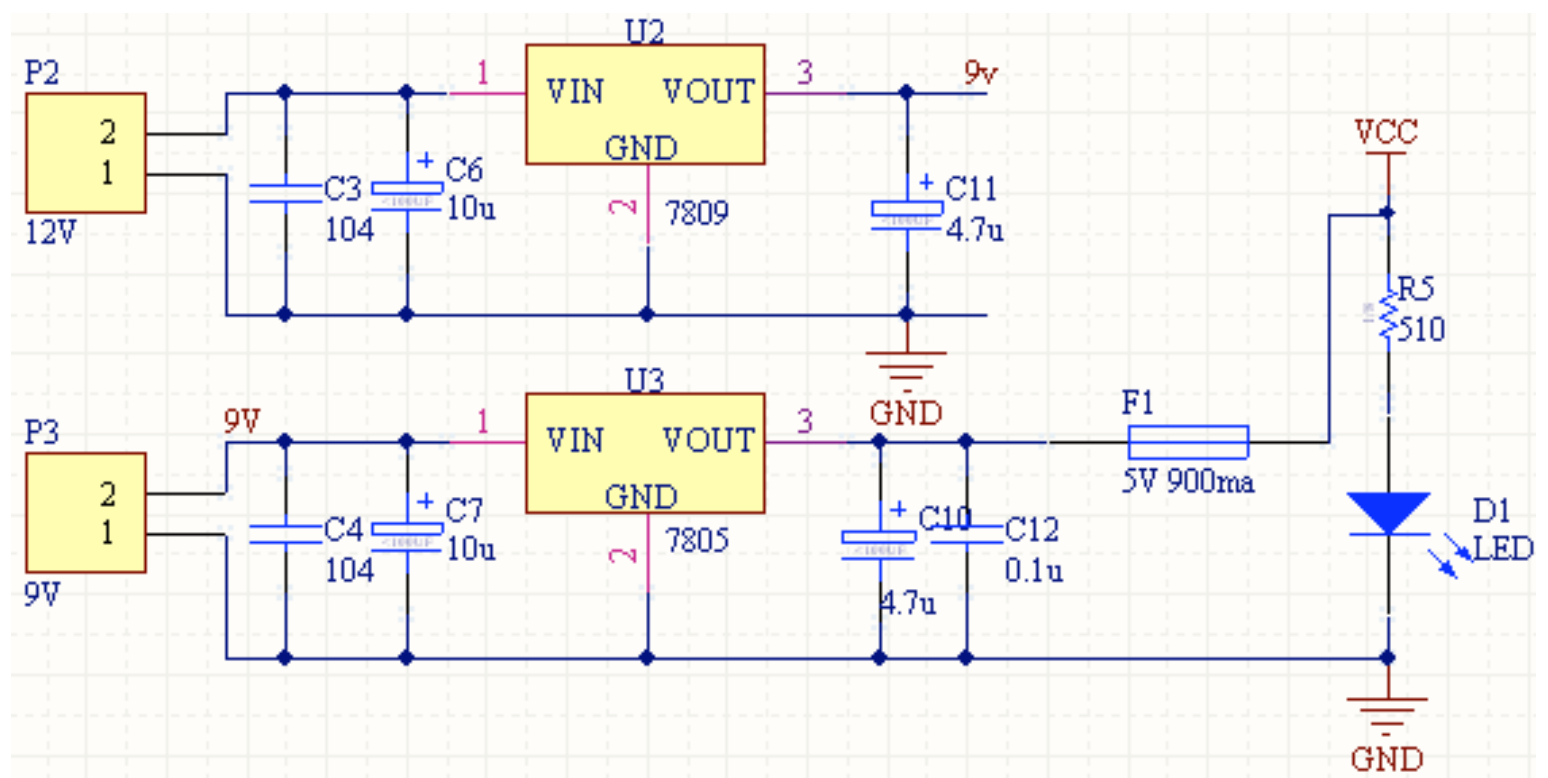

Fig. (8). Power supply circuit.

When the raindrop drop to humidity-sensitive film, output is low, Controller receives the low level signal, forward drives two motors, makes the hanger close up and cover curtain down. The clothes are protected; the sun shines again after rain, the water is evaporated, sensor output high level signal, Controller receives this high level signal, controls two motors reversal, makes the cover curtain upwards roll and the hanger outspread for drying. The rain sensor hardware circuit is shown in Fig. (9). The rain sensor with two-point arrangement modes, the left and right ends of hanger is respectively arranged sensor; the sensitivity of the sensor is improved. Only when the two sensors are effective, controller outputs the information.

In addition, when the rain is detected, the hanger is not only able to fold and shelter, the buzzer can also beep to tip indoor host.

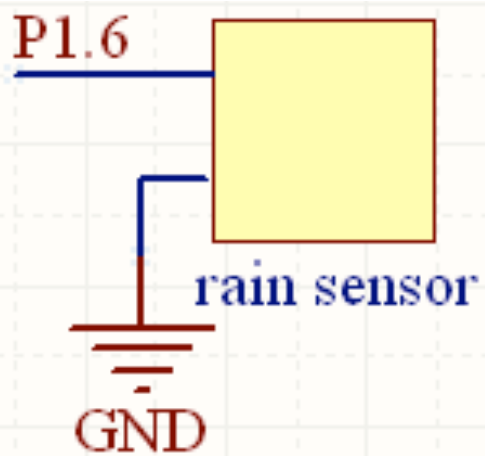

Fig. (9). Rain sensor hardware circuit

The rain sensor has two terminals. One terminal connects the GND, another terminal connects pin 1.6 of single chip. When it rains, the pin 1.6 of single chip receives low level signal that coming from rain sensor. Pin 0.7 of single chip which is controlled by program outputs high level signal. Buzzer sends out sound in order to tell people that it is rain- ing. At the same time, the hanger will be automatically closed. When it stops raining, the pin 1.6 of single chip receives high level signal that comes from rain sensor. Pin 0.7 of single chip which is controlled by program outputs low level signal. Buzzer will not sound and the hanger will be automatically opened. The buzzer circuit is shown in Fig. (10).

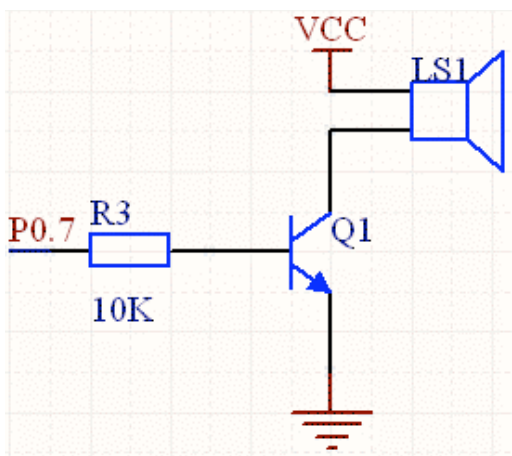

Fig. (10). Buzzer circuit

\section{Temperature Control Circuit}

In order to achieve the anti-exposure function of the intelligent hanger, it is needed to real-time monitor environment temperature. The temperature signal susceptible to interference causing measurement error influences the accuracy of measurement. Therefore, in the temperature measurement system, strong anti-interference ability DS18B20 chip is adopted to measure environment temperature. The range of test temperature is wide, high resolution (the maximum resolution of up to 0.0625 degrees C), Negative voltage characteristics. Unique single-wire interface requires only one port pin for communication. The user can define alarm settings, it will alarm to tip indoor host if the temperature exceeds the expectation of program limit temperature.

DS18B20 has three connection terminals. One terminal connects the VCC, another terminal connects the GND, and 
the third terminal connects signal line. The hardware circuit of the DS18B20 is shown in Fig. (11).

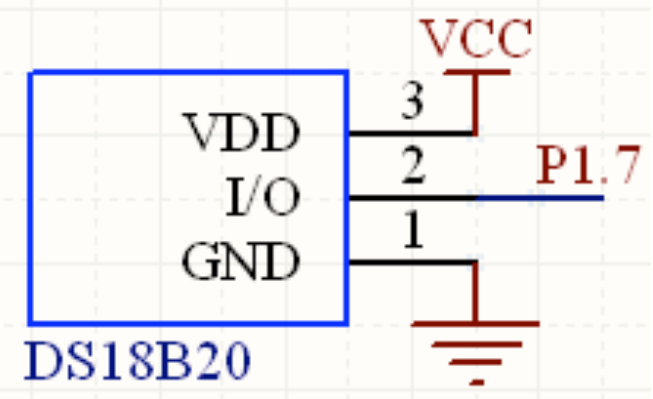

Fig. (11). Hardware circuit of the DS18B20

\section{Motor Drive Circuit Design}

Stepper motor is adopted. Single chip outputs very little current and the current cannot drive the stepper motor. The driver is used between single chip and stepper motor. Main motor adopts THB6064 as its driver chip. Deputy motor adopts THB6128 as its driver chip. Driver chip has the advantages of low power consumption, Stable operation and so on.

Driver input signal interface has two kinds of connections. Users can adopt common anode connection or common cathode connection according to their need. Through the actual test, more current can be produced if we adopt common cathode connection. The wiring of the main motor driver is shown in Fig. (12). Pulse input signal is connected to Pin 1.0 which is named CP-. Direction signal is connected to Pin 1.1 which is named DIR-. Enable signal is connected to Pin 1.2 which is named EN-.CP+,DIR+ and EN+ are connected to VCC. When pulse signal is connected to CP - and high level signal is connected to $\mathrm{EN}$-, the motor can rotate. Motor makes reverse rotation if low level signal is connected to DIR+. CP-、DIR-、 EN- of the deputy motor driver respectively connects to the microcontroller P1.3-P1.5.The wiring diagram is shown in Fig. (12).

The system must rely on software program to realize the expected requirement. The software program is mainly composed of main program and subroutine composition. Each subroutine assumes certain function. Main program flow chart is shown in Fig. (13).

\subsection{Overall Entity Diagram of the Intelligent Hanger}

Through the mechanical structure and control system design, the final overall entity diagram of intelligent hanger is shown in Fig. (14).

This intelligent hanger without affecting the normal drying clothes has the function of automatically taking shelter from rain and anti-exposure. The hanger with unique design adopts outspread wings structure, when the wings of hanger close up, it can reduce the rain wind area. a unique cover curtain structure is adopted and can outspread or fold automatically. The screw rod and motor combination of lifting

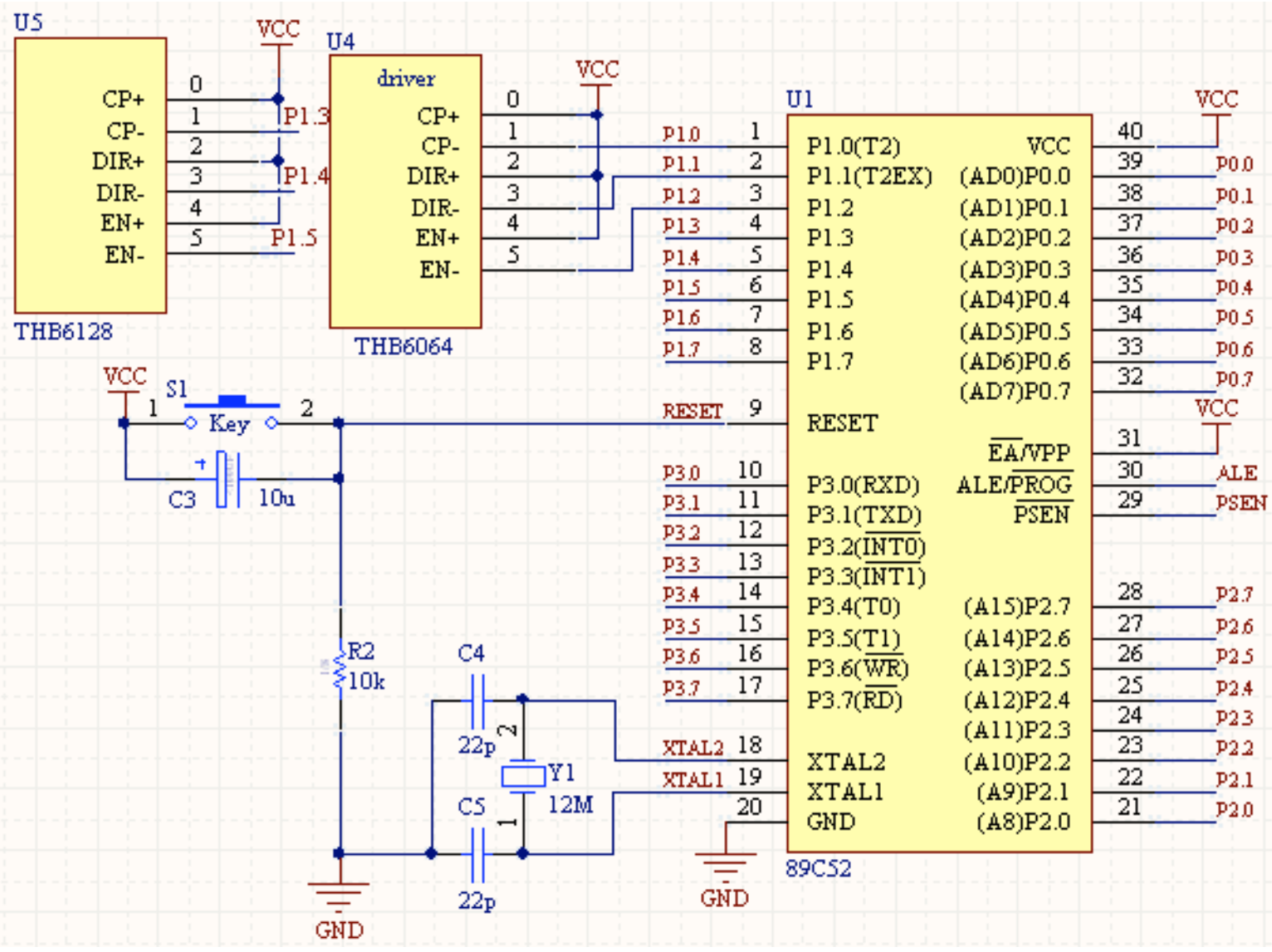

Fig. (12). Circuit of the motor driver 3.2 Software program design 


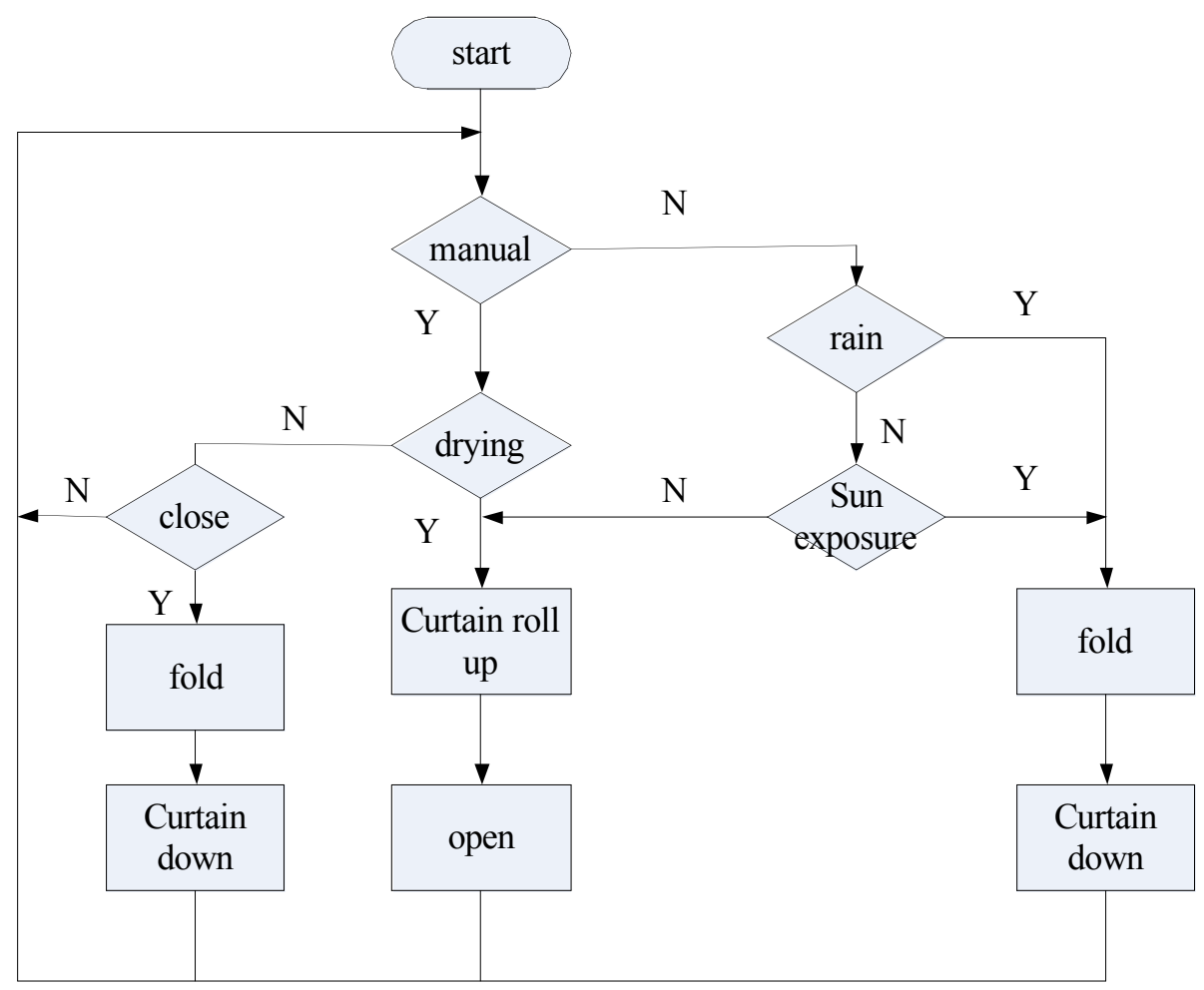

Fig. (13). Main program flow.

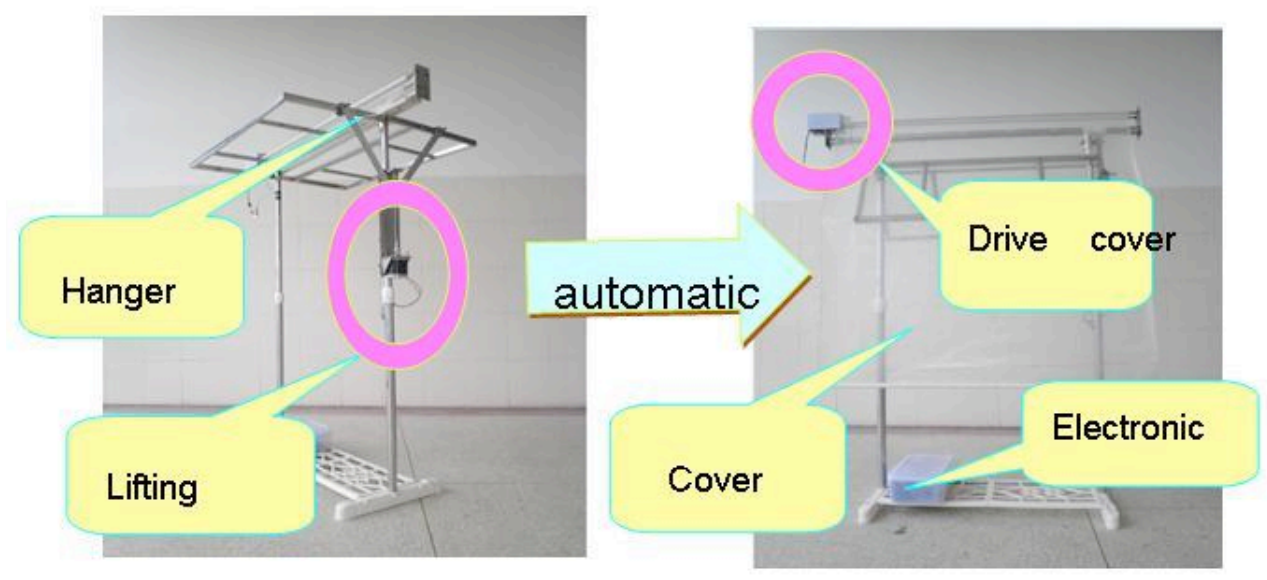

Fig. (14). Overall entity diagram of intelligent hanger.

mechanism is used, it has the function of avoiding the motor burn out. The hanger is easy to move, structure of the hanger is simple and easy to operate.

\section{CONCLUSIONS}

The hanger has the advantages of compact structure, simple process, convenient use, stability and safety, low cost and other characteristics of the intelligent hanger.

The intelligent hanger can simultaneously achieve the rainproof and drying function, simple mechanism, convenient control, cost-effective, easy to carry, material is bought easily, fast response speed and high security. It can increase the clothes airing space, avoid rain automatically and reduce the rain wind area more effectively. Now the entity of intelligent hanger has been made, it can automatically take shelter from rain, anti-exposure well in actual use.

\section{CONFLICT OF INTEREST}

The authors confirm that this article content has no conflicts of interest.

\section{ACKNOWLEDGEMENTS}

Youth fund of Nanchang institute of technology under Grant No. 2012KJ011 sponsored this paper. The authors deeply appreciate the supports.

\section{REFERENCES}

[1] P. Qingming, and D. Zuowu, "The Design about an Intelligent Clothes Rack with the Faculty of Rainproof、Insolationproof and Drawing Back Automatically at Night", Dev. Innov. Mach. Elect. Prod., vol. 20, no. 6, pp. 79-81, 2007;

[2] Y. Youping, "Design of 89c51 mcu-based control system of intelligent clothes rack", Mech. Eng. Autom., vol. 6, 2011; 169(6): 126-128. 
[3] Z. Qian,and S. Xiao, "Design of intelligent clothes rack based on MCU", Mech. Eng. Autom., vol. 6, 2012; 175(6): 152-156.

[4] W. Yinku, C. Jianguo and Z. Chunliang, Single-chip Microcomputer Principle and Development Technique. Xi An: Xi An University of Technology Press 2007.

[5] W. Fujun and P. Songfeng, Single chip microcomputer Principle System design and application, He Fei: University of Science and Technology of China Press 2001.
[6] W. Yongmei, H. Anlin and W. Weiping, Pro-e the Chinese Version 4.0 from the Door to Master, Publishing house of electronics industry 2008.

[7] W. Weibo and W. Jinguang, "Intelligent Clothes Rack", China Comput. Commun., vol. 12, p. 102, 2011.

[8] W. Kun and H. Xiaobo, Mechanical Design, Beijing: Higher Education (Press).

Received: July 02, 2013

Revised: July 07, 2013

Accepted: July 14, 2013

(C) Jia and Chu; Licensee Bentham Open.

This is an open access article licensed under the terms of the Creative Commons Attribution Non-Commercial License (http://creativecommons.org/licenses/by-nc/3.0/) which permits unrestricted, non-commercial use, distribution and reproduction in any medium, provided the work is properly cited. 